\title{
Team-Based Learning: A Promising Strategy for Use in Online Distance Education
}

\author{
Rozangela Maria de Almeida Fernandes Wyszomirska, Renato Jabour Pennaforte, \\ Fernando Gomes de Barros Costa, Eliane Monteiro Cabral Warren, Antonio Quintas-Mendes
}

Universidade Estadual de Ciências da Saúde de Alagoas, Universidade Federal de Alagoas e Centro Universitário Tiradentes, Maceió, Brazil

Email: rozangelaw@yahoo.com.br,renatojp2013@gmail.com,fgbcosta85@gmail.com, elainewarren@yahoo.com,quintasmendes@gmail.com

How to cite this paper: de Almeida Fernandes Wyszomirska, R. M., Pennaforte, R. J., de Barros Costa, F. G., Warren, E. M. C., \& Quintas-Mendes, A. (2021). Team-Based Learning: A Promising Strategy for Use in Online Distance Education. Creative Education, 12, 278-292.

https://doi.org/10.4236/ce.2021.121020

Received: December 19, 2020

Accepted: January 26, 2021

Published: January 29, 2021

Copyright $\odot 2021$ by author(s) and Scientific Research Publishing Inc. This work is licensed under the Creative Commons Attribution International License (CC BY 4.0).

http://creativecommons.org/licenses/by/4.0/

\begin{abstract}
Beginning in the 2000s, active methodologies began to emerge in some medical schools, evolving from the traditional teaching methodology to the use of methodologies, such as team-based learning (TBL), in which the student acts as the protagonist of his learning. In 2020, with the outbreak of a pandemic that required measures of social distance, a new reality emerged in the educational field, which was the adaptation of strategies traditionally carried out in person for the online format. The purpose of this article was to structure and execute a TBL design, based on the principles of online distance education and the use of technologies. The article presents a brief review of the TBL methodology and the design of the strategy in the online format, with a roadmap to adapt the execution on known platforms and available for online use. The article also presents reports of the utilization of TBL online through the Moddle platform in the first semester of the fourth year of a medical school course. In a second semester of the first year of a Psychology course and in a pharmacology graduate course for a nursing class, the Team-based learning was conducted by Microsoft's platform. It is worth mentioning that for Moddle, the questionnaires to guarantee preparation and response in groups were carried out on the platform itself, while for TEAMS, the questionnaires were carried out through another platform, Socrative, which proved to be agile and compatible. We conclude that the TBL methodology is perfectly feasible in the distance modality, presenting significant learning, but some difficulties are observed, such as the need for a safe and efficient internet network, as well as the dependence on the student's and teacher's digital knowledge.
\end{abstract}

\section{Keywords}

Adult Learning, Distance Education and Online Learning, Teaching/Learning 
Strategies, Improving Classroom Teaching, Information Literacy

\section{Introduction}

The medical teaching model in Brazil, in the $20^{\text {th }}$ century, was based on principles that favored scientific and technical training, where factors that produced diseases were emphasized and that stimulated professional specialization early. In this model, the teacher/student relationship in the teaching/learning process took place in an empirical way, where the knowledge was in the teacher and the student played a role of sensory receiver of this knowledge (Cutolo \& Delizoicov, 2003). For Silva (1995), the pedagogical practice for the teacher almost always involved teaching techniques, using audiovisual resources and assessment instruments.

As a counterpoint, a new paradigm emerged, in the late 1990s, considering a more contextualized medical education regarding undergraduate health professional programs, considering the social, economic and cultural dimensions of the population's life (Campos et al., 2001). This model was guided by the construction of an integrated curriculum, through the adoption of teaching-learning methodologies centered on the student as the subject of learning, with the teacher being the facilitator of the knowledge construction process (Lampert et al., 2009). One of the pillars of this approach, meaningful learning, was created by Ausubel, when he identified that the prior knowledge of each student (his cognitive structure) would be the variant that, in isolation, would most interfere with his learning (Legrand, 1976). In Brazil, Paulo Freire had also emphasized that the knowledge brought by students would be a considerable driving force for the incorporation of new knowledge (Freire, 1974).

In short, while traditional learning was concerned with "what" should be transmitted and used the method of repetition and memorization of students, meaningful learning was concerned with "how" the student will acquire knowledge and postulated that he learns by doing thus developing not only knowledge, but also skills (skills) and attitudes (behaviors), in addition to encouraging early practice, reducing the gap between graduation and the work to be performed by the future professional (Borges \& Alencar, 2014).

Active methodologies use activities that motivate students to build knowledge and at the same time develop skills and attitudes that go beyond simple knowledge. However, it is important to note that there are decisive factors for its pedagogical success or failure. The first, and most important, is the imperative need for students, the protagonists of the process, to understand and be willing to use them. Another factor concerns the teacher, who must select motivating and appropriate activities for each pedagogical objective, clearly explain the purpose of the activity, create situations for debate, evaluate the progress of individual learning at regular intervals and, above all, be prepared for unexpected 
changes course, at any time during the teaching process (Barbosa \& de Moura, 2013). For the authors, active learning should favor in student the activities of listening, seeing, asking, discussing, doing and teaching based on a modification of a Chinese proverb, performed by Silberman (1996): What I hear, I forget; What I hear and see, I remember; What I hear, see and ask or discuss, I begin to understand; What I hear, see, discuss and do, I learn, developing knowledge and skill; What I teach to someone, I master with mastery.

Active learning strategies only came to be incorporated into medical curricula, after studies showed that the teacher's commitment and commitment in the didactic-pedagogical relationship influenced the student's learning (Lundberg, Martenson, \& Brostom, 2000), as well as the need for preparation pedagogical teaching, including the incorporation of educational programs in medical schools (Bligh \& Anderson, 2000). Many schools then reduced the number of lectures in their curricula and introduced methods, such as problem-based learning, followed by team-based learning, which uses an effective study strategy in small groups working independently in high-class classes number of students and project-based learning (Searle et al., 2003). These active methodologies adopt techniques and activities that arouse curiosity and creativity, as students bring new approaches to the proposed problems. It is these elements that serve as the basis for new discussions, stimulating the student's commitment and the feeling that they are in some way, owners of the theme (Borges \& Alencar, 2014).

Within this context of transforming teaching in medical schools, the vast majority of medical courses in Brazil promoted changes in their teaching-learning model. The first experiences came with the adoption of problem-based learning (Gomes et al., 2009). Team-based learning, from Team-Based Learning (TBL), was introduced later, with the perspective of replacing expository classes, centered on the teacher, and to promote active and student-centered learning, with some changes in the format, according to reports on the implementation of the methodology (Bollela et al., 2014; Krug et al., 2016; de Oliveira et al., 2018). The experiences of using this teaching methodology, in Brazil, have always used the traditional classroom modality and in the literature we do not find available articles or experience reports in the distance modality.

In early 2020, the world was shaken by the arrival of the COVID-19 Pandemic with the determination of social isolation and the traditional classroom with face-to-face classes suspended. In Brazil, the pandemic broke out with greater severity from March 2020 and on March 17, Ordinance MEC No. 345 authorized the substitution of traditional face-to-face classes with online classes in digital media while the pandemic situation lasts (Brazil, 2020). Faced with this situation, medical professors who were working with active methodologies in person, started to discuss how they could transpose traditional classroom activities with strategies such as TBL, to the online format.

Carrying out a TBL, which is successful in its execution, is a task that requires delicate and systematic planning. In typical situations, with face-to-face meet- 
ings, even if well planned, their execution can bring expository classes. The process of transposing to an online format could be problematic, given that we are not aware of previous successful experiences. Thus, the objectives of the present study were to structure a TBL design based on the principles of online distance education, respecting the step-by-step in which the methodology was presented for the traditional classroom format and reporting how the sessions took place.

\section{Theoretical Reference}

A brief review was carried out on the TBL strategy, in particular its step-by-step as well as on online distance education.

\subsection{TBL in Person Mode}

Team-based learning was developed in the 1970s by Larry Michaelsen for business courses with large numbers of students, gaining attention in medical education, starting in the 2000s, with an increasing number of medical schools in several countries adopting the TBL in different formats (Parmelee, Michaelsen, \& Hudes, 2012).

Haidet et al. (2012) proposed a guide with guidelines identifying the seven main elements of the design of the TBL method and related them to educational principles that maximize student involvement and learning in teamwork. The highlighted elements were team building, guarantee of preparation, teacher feedback, problem solving in the classroom, application of concepts, using principles known as 4 Ss (significant problem, same problem, specific choice and report simultaneously), structure of evaluation and peer review. The methodology provides learning opportunities to the student through the creation of a sequence of activities that includes steps prior to the meeting with the teacher and the steps that will be accompanied by the teacher, with the students being responsible for preparing the study before class for collaborating with his team members to achieve the learning objectives, while the teacher is a mediator or instructor, who must be an expert on the subject. Finally, one of the goals is for students to learn to work in teams without the need for additional instruction or facilitators who are experts in group processes.

In 2012, Parmelee et al. (2012), also proposed a practical guide, with a set of step-by-step recommendations on how to build a TBL module:

- Individual guarantee or Pre-preparation, students prepare in advance for activities during classes (previous readings or watching an experiment, conference, film, video, conducting an interview, etc.).

- Preparation guarantee, preparation assessment, individually and in teams.

o Individual preparation guarantee test, 10 to 20 multiple choice questions;

o Group preparation guarantee test, using the same questionnaire;

o Discussion to answer questions and clear doubts.

o Teacher's conclusions. 
- Application of Concepts, through case study, discussed in groups and where it can be carried out or not, plus a questionnaire (multiple choice, true or false or short answer).

In 2014, Burgess et al. (2014), carried out a systematic review on the extension, design and practice of TBL programs in medical schools, which revealed extensive variations both in the design, in the way it was implemented and in the reports of TBL programs. Of the 20 articles included in the review, 14 had described a classic TBL program and 6 described programs with modifications in 10 different countries, with no study in Portuguese being included. Classes ranged from 20 students in a psychiatry internship to 240 in a clinical application course in basic sciences. Two methods of random allocation were observed the random selection of student numbers and the use of a random list of whole numbers assigned to an alphabetical list. Study preparation and Pre-preparation, followed, in most articles.

\subsection{Online Distance Education}

In Brazil, the first initiative in Distance Education (DE) appeared in 1979, at the University of Brasília and with the publication of the Law of Directives and Bases of Education LDBE, Law no 9.394, of December 20, 1996, was described as a modality teaching and continuing education (Brasil, 1996). In 2005, the Decree $\mathrm{n}^{\circ} 5.622$, of the Ministry of Education, regulated EAD, as an educational modality in which didactic-pedagogical mediation in the teaching and learning processes occurs with the use of information and communication means and technologies, with students and teachers developing educational activities in different places or times. Medical education started to incorporate some initiatives in this direction, with some specific initiatives. As of 2018, the Ministry of Education (MEC) published Ordinance No. 1428/2018, which in its Article 3, provided for the provision, by Higher Education Institutions, IES, of disciplines in the distance modality in courses of face-to-face graduation, limited to $20 \%$ of the total course load and provided specific requirements are met (Brasil, 2018).

Amarilla Filho (2011), when reviewing distance education from the point of view of a methodological and didactic approach and from virtual environments, defined Distance Education as an open, flexible and formative teaching that is established by a temporal and spatial dichotomy which can be overcome by human technologies, aiming at the integration and interaction of teaching-learning processes through specific methodological and didactic processes. Furthermore, he also considered that in virtual learning environments, the student has to change his passive, dependent and receptive posture, to be more active, looking for information and interacting with colleagues and tutors.

For Quintas-Mendes and Wyszomirska (2018) the intense social interactivity of computer networks and information technologies allowed the development of less individualistic and more collaborative pedagogical and communication practices, which boosted the appearance of new concepts, such as virtual learn- 
ing environments, virtual learning communities, Online Education, Online Distance Learning, where there is a break with learning centered on self-teaching and content distribution to invest in approaches where participation and interactivity between teachers and students are fundamental.

In an article in which they described the pedagogical model resulting from technological innovation operationalized at the Portuguese Open University, Amante and Quintas-Mendes (2016), reported as a basis for the referred model, four major lines of strength: student-centered learning, as an active individual, builder of knowledge; flexibility, which they consider one of the advantages of distance learning, as it allows the student to have access to content and learning activities or to solve the related tasks in a flexible way, without time or displacement imperatives; the various forms of interaction, especially between the students themselves, which allows the creation of group discussions within each virtual class, as well as the use of active learning strategies, in order to stimulate student initiative and involvement; and digital inclusion, through the promotion of educational strategies that contribute to the acquisition and development of students' digital literacy.

\section{Methods}

This is an exploratory study with a qualitative approach, aiming to use the TBL strategy in the online format. To achieve the objectives, a study group formed by professors with experience in approaching the traditional classroom TBL methodology, carried out a bibliographic review and collected information about the available technologies, in the institutions where they worked.

\subsection{Study Group for Preparing TBL Script in Online Format}

The study group consisted of professors, who are also the authors of the present study, two professors from the medical course at a federal public university and one professor at a private university in Brazil. In addition, as part of the group there was a professor specialized in online distance education from the Open University of Portugal and a master's student. After surveying the technologies available at their universities and reviewing the literature they elaborated a script proposal for TBL online.

The next step was the application of an online TBL session, using the elaborated script, in one discipline of the medical course, as well as in another discipline of the psychology course and in a discipline of a graduate nursing course. The teachers responsible for conducting the TBL sessions online, later reported the experience, identifying strengths and weaknesses. The activities for these disciplines took place between the months of August to November 2020.

\subsection{Survey of Available Technologies}

The technologies available in the institutions where the teachers worked were listed, according to the specific audio and video resources available, as well as for 
being easy to handle by students and teachers and for being technologies used with Internet.

\subsubsection{Moodle Platform}

It is an open software, for learning management and collaborative work, allowing distance courses and disciplines to be held or support for traditional classroom activities presenting communication and information management interfaces. On the platform, it is possible to create living spaces (forums, chats, and web conferences), interaction (spaces for carrying out activities related to the contents studied), text repository, presentations, videos, among others, as well as spaces for evaluation. It is designed in a modular way and allows great flexibility to configure, add or remove features. This software is continuously developed by a community of thousands of programmers worldwide, including a support group for users, as well as the addition of new features. A foundation (http://www.moodle.org/) and a company (http://www.moodle.com/) provide support, respectively, for the development of the software and its translation into dozens of languages, and professional support for its installation.

\subsubsection{Socrative}

Allows the teacher and students to interact, from the smartphone, tablet or computer. Enables the application of activities in the classroom or as an extra-class task (http://www.socrative.com/). Students can answer questions from their devices, if they have an Internet connection. Participants can connect using a number or a class name provided by the teacher, with a limit of up to 50 people simultaneously. The platform requires registration and allows you to archive reports and maintain control over the number of subscribers. Its operation is done through at least two modalities Socrative Teacher and Socrative Student, available on Socrative's website or in the application store of the mobile device.

\subsubsection{Microsoft TEAMS}

This platform is integrated with the Office 365 suite of services and applications, which include Word, Excel, Power Point, and others. It was designed for the corporate environment, but it has been gaining space in the global educational environment, having incorporated several features of the popular Skype, in addition to including in a single location, features that can be used in distance learning: sending material, video calls, registration of participants and virtual storage in a single window, with navigation through "boxes", similar to what is observed in Windows itself. It also has cloud storage, private and community chat, team management, sending and receiving files, planning and activity calendar, all in one environment.

\subsubsection{Big Blue Button}

It is free software (http://www.bigbluebutton.org/) for hosting web conferences and virtual classes. Its platform is based on Adobe Flash, with several features available in the presenter's view. 


\section{Script for TBL Online}

A design was built using the internet, following the established principles of TBL methodology:

- Individual or Pre-Preparation Guarantee, the files on the topic discussed would be previously available on any of the platforms available at the institutions.

- Guarantee of preparation, the test of guarantee of individual preparation must be carried out using the questionnaire activity of the Moodle Platform or through a socrative application.

- Guarantee of group preparation, the discussion in small groups can be carried out through CHAT activity on the Moodle Platform or through web conference rooms, being the test of guarantee of group preparation carried out through questionnaire activity of the platform or a Socrative application.

- Discussion for the removal of doubts and conclusions of the teacher, carried out through the web conference room. After discussion and removal of doubts, the teacher gives his conclusions, highlighting the points that left more doubts.

- Application of Concepts, clinical case study through FORUM or CHAT on the Moodle Platform, whether it can be followed or not by a questionnaire (multiple choice, true or false or short answer), or even on the same web conference for the teacher's conclusions, a clinical case with discussion and conclusions can be presented.

\section{Report of Pedagogical Experience Session with TBL Online}

\subsection{Online TBL Session in the Medical Course at a Public Institution}

TBL online was introduced in an elective discipline, "Differential diagnosis in Gastroenterology and Hepatology", offered to students attending the $4^{\text {th }}$ year of the medical course at the Federal University of Alagoas, Brazil. The course was fully developed on the Moodle Platform, in weekly units, with 7 themes, one content to be developed per week and using different digital strategies. One of the strategies applied was TBL online, for the content of chronic liver diseases. In the construction of the discipline in Moodle (Figure 1), PASTA AND URL resources were used to insert the material for previous study, with text files and a video, related to the subject. In addition, $\mathrm{BBB}$ activities were used for the large meeting and for discussion in small groups, and the QUESTIONNAIRE for individual and group warranty tests. BBB has several functionalities in the same environment, being able to open to 8 parallel rooms. On the day and time previously agreed, the two teachers responsible for the discipline coordinated the large meeting, explaining to the students, how the activity would develop, as well as the criteria for the formation of study groups and they established an agreement on other minimum rules of coexistence. For both teachers and students, this was the first time they would be using the strategy in the online format. Next, 
TBL ONLINE

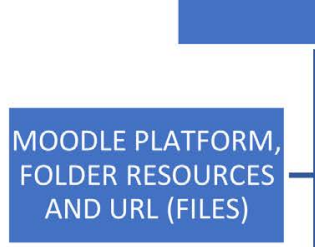

BBB (SESSION OPENING)

N

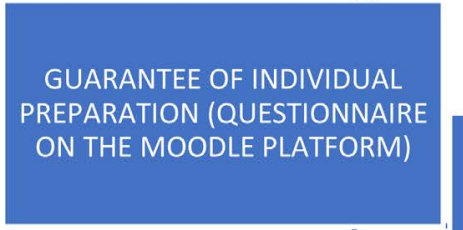

GROUP PREPARATION

GUARANTEE (BBB FOR SMALL

GROUPS AND QUESTIONNAIRE)

ON THE MOODLE PLATFORM

BBB ON THE MOODLE PLATFORM

(SIMULATED / REAL CLINICAL

CASE, DISCUSSION

CONCLUSIONS)

Source: By author.

Figure 1. Script of the online TBL session using the Moodle platform.

students answered the individual questionnaire on the Moodle platform, with a time limit of 10 minutes. The next step was to free up access for students to the virtual small rooms at $\mathrm{BBB}$ and under the supervision of the two teachers, discussed the topic in groups of up to 7 students, for a period of 50 minutes and after the discussions were closed, they answered the group guarantee test (10 minutes time), using the QUESTIONNAIRE activity on the Moodle platform once again. After completing this step, all students returned to the large virtual room. At this moment, the teachers presented the statistics of the results of the questionnaires (Figure 2), with an average of correct answers of 65/100, when the individual questionnaire and $98 / 100$ for the group questionnaire. This is another feature of the Moodle platform, as the result of the performance of the questionnaires is in real time. Then, all questions were answered with presentation of simulated or real cases, by one of the teachers. Listening to students regarding their thoughts about the online methodology format, they considered the format to be a great strategy for their learning, easy to adapt, pointing out some difficulties, such as the oscillation of the internet network and the time length, taking longer than in the traditional class format to complete all the required steps. For the teachers, it was a rewarding experience, showing that it was possible to execute, requiring 
great care with the details when structuring the platform.

\subsection{Experience in a Private Institution}

The TBL online methodology was used both in the Collective Health discipline in the $2^{\text {nd }}$ semester of Psychology, and in the Pharmacology discipline for the ICU in a graduate course for nurses in the city of Arapiraca-Alagoas, Brazil.

\section{AVERAGE OF CORRECT ANSWER QUESTIONNAIRES}

120

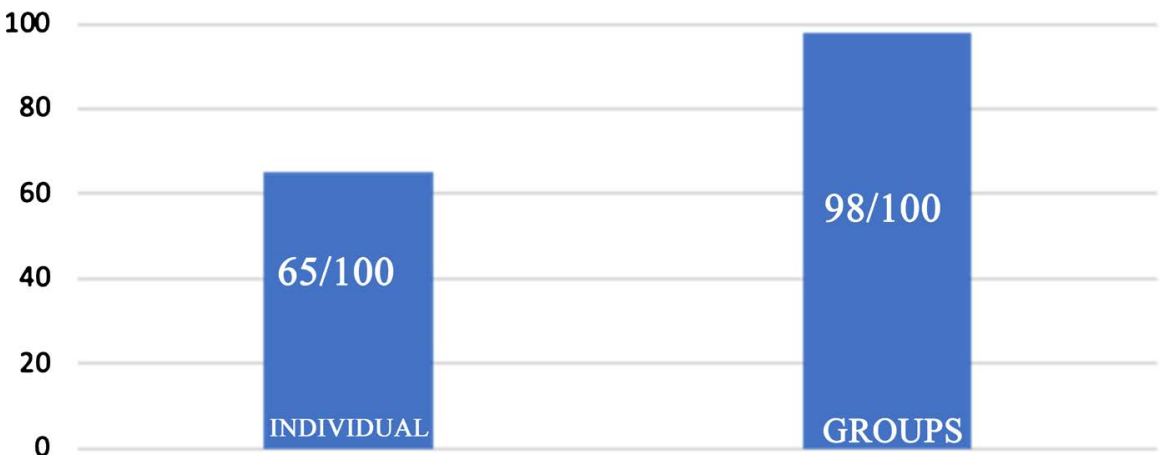

Source: By author.

Figure 2. Average of correct answers for individual and group questionnaires.

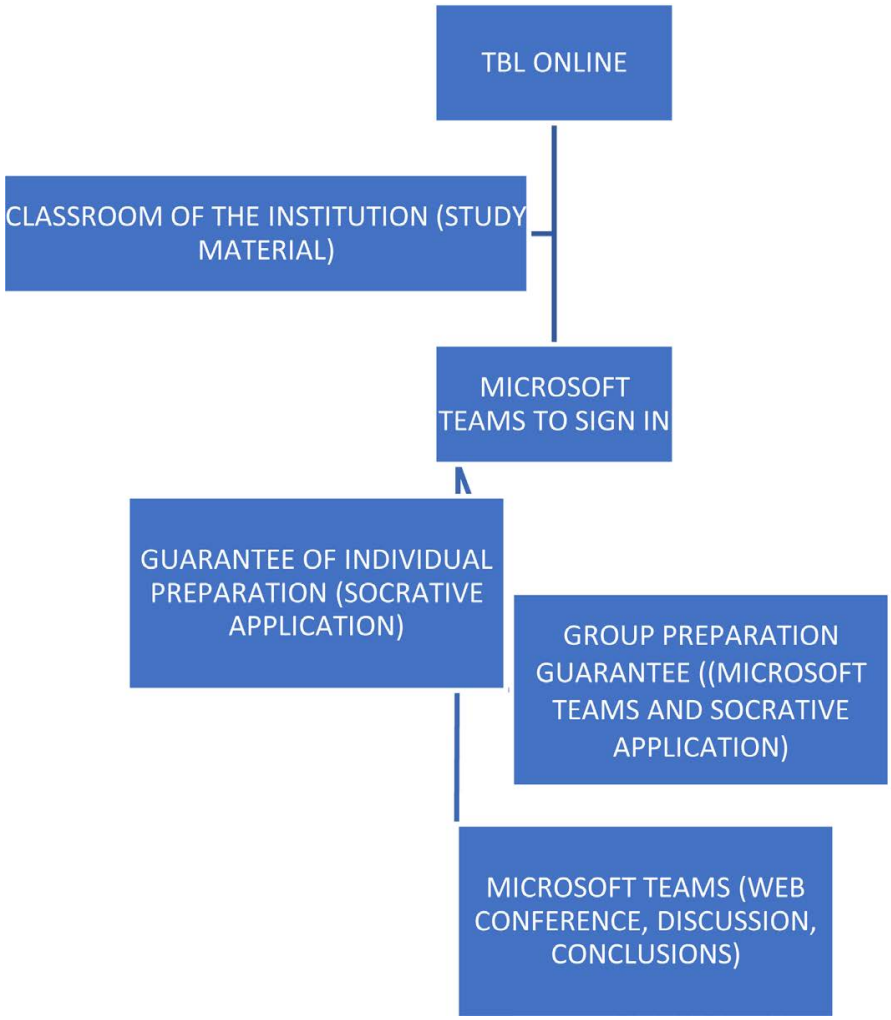

Source: By author.

Figure 3. Script of the online TBL session using the Microsoft Teams platform and the Socrative application. 
Some adaptations were necessary, so that the execution of the methodology could follow the maximum similarity with the traditional class with face-to-face format. Even in the face-to-face modality, we make the previous material available on IES platforms, as usual. On the day of the meeting, we started the pre-test (Figure 3), or guarantee of individual preparation, using the online application Socrative ${ }^{\circledR}$, as it can organize participants by name, in addition to allowing real-time observation of response statistics from the students. So, this adaptation was not so difficult, just changing the way the results are projected for viewing by the class, because if in the face-to-face environment, we use a data-show projector, in the remote environment, the platforms allow the facilitator's screen to be shared. The biggest methodological challenge, found in TBL online, was the moment of division into smaller groups, for the discussion of the content proposed by the facilitator. We identified some implementation difficulties, which are inherent to the remote model, one of which is the division of groups, as the teacher has difficulty identifying the students' profile, thus compromising the heterogeneity that is recommended in the group of groups. Another complicating factor was the location of the groups' private meeting. If on one hand projecting materials for an entire class is not a problem, as all remote class tools have screen sharing mode, with no visualization selectivity. Some tools, such as Microsoft TEAMS, in the corporate version, have a highly organized and intuitive way of managing students. Teams are divided by topics, subjects, or electives. The big difference when accessing the desired team, is that all the features are in the same environment, without the need to open more "tabs" or other programs, except the class materials such as texts or presentations, but which can also be integrated to that environment. It is worth mentioning that in this environment, with few clicks, private rooms linked to the main room can be created, called by the channel TEAMS, and that the participants in each channel have the independence to open video calls and thus talk in a totally private way.

This way, a great obstacle to the methodology is solved, since the teacher/facilitator creates the rooms and allocates the group or can even allocate a student per room and making the student the owner of that group, giving autonomy for the student to create a group, inviting other students, thus reducing the teacher's work and also exercising the student's autonomy. The creation of these channels, as private rooms, does not interfere with the dynamics of the general channel of the team, functioning with total independence, and since the teacher is the owner of the team, he can at any time enter the private channels, either to guide, or for any clarifications, as well as extinguishing these channels. It is worth remembering that before any execution of activities, the whole class agrees on a series of social norms to be followed, which are also quite common to the traditional classroom with face-to-face model. After conducting the group discussions, the mediation stage with the whole class follows, and the functionality called "raising hands" can be used, which facilitates the organization and call of the class for participation. This tool identifies the sequence in which the par- 
ticipants "raise their hands" and can be called in that order. Thereafter, the methodology follows smoothly, even for a large number of participants, keeping in mind the agreement of coexistence, as well as the rules accepted by all, are fundamental for the development of the learning proposed by the methodology.

\section{Discussion}

In 1987, Cross (1987) considered that students learn more when they are actively involved in learning than when they are passive recipients of instruction. The TBL was defined by Parmelee et al. (2012) as an active instructional strategy for small groups through a sequence of activities that include individual work, teamwork and immediate feedback. In Brazil, this strategy in the traditional classroom format was incorporated into medical education, especially after the National Curriculum Guidelines (DCNs) of Medicine, in 2014, suggested the use of active methodologies privileging the student's active participation in the construction of knowledge and integration between the contents (Brasil, 2014). In the present study, we intend to demonstrate the feasibility of carrying out this strategy, in all its steps, in the online format.

Educators have been encouraged to create learning environments by incorporating active strategies. Rao and DiCarlo (2001), carried out a study to assess the effectiveness of team-based learning, comparing the performance of a class of 252 students in which active learning strategies were used with a class of 84 students who attended a traditional class in the format of lecture. The results showed that students who learned using active learning strategies performed significantly better than students who learned using the traditional classroom format.

There are countless experiences accumulated with the use of TBL in the traditional classroom format, in undergraduate and graduate courses, with an apparent good impact on students. Bollela et al. (2014), considered TBL as a strategy capable of promoting meaningful learning, based on central principles of adult learning, valuing the individual responsibility of the students. In another study, de Oliveira et al. (2018), also considered that TBL was useful in the learning process and in the assessment of students' training.

Team-based learning (TBL) in medical education has emerged in recent years as an educational strategy to enhance active learning and critical thinking even in large basic science courses. Although TBL consistently improves academic results by shifting the instructional focus from the transmission of knowledge to the application of knowledge, it also addresses a number of professional skills that cannot be achieved or assessed through classroom-based instruction. These 12 tips provide the reader with a set of specific recommendations that, if followed, will ensure the successful design and implementation of the TBL for a unit of study.

With the need for changes in the teaching modality, due to social isolation, resulting from the outbreak of the pandemic COVID-19, it would not be fair to simply move from traditional classes to remote lectures, abandoning the use of 
the active methodologies adopted and proven efficient. Thus, it became imperative to look for ways to integrate active methodologies with the use of digital platforms and technologies. This study emerged to respond to this demand, for a proposal to use an active strategy in online education.

In 2010, Parmelee and Michaelsen (2010), considering that TBL would improve academic results, changing the instructional focus from the transmission of knowledge to the application of knowledge, as well as addressing professional skills. The authors organized 12 recommendations that would contribute to the success of TBL, which were observed by our study group, when the script and the structuring of the online strategy were developed. First, the design of the discipline in which we use TBL was intended to enable the student to use information for clinical reasoning in concrete situations, which would be in line with a strategy that allowed the application of knowledge. Following the recommendations, we created individual and group activities with application exercises that promoted deep thinking and engaged and content-focused discussion. The entire preparation guarantee process was meticulously prepared. We present the strategy to the students, agree on rules of coexistence and rules for the formation of groups, in addition to highlighting the responsibility of each one for the success of learning. The appeal process, for removing doubts and conclusions, was extensive, with discussion of a real or simulated clinical case.

\section{Conclusion}

The present study presented a roadmap for the realization of the TBL completely online, which followed all the existing steps and recommendations for the traditional classroom format, without any loss to the methodology. By making it possible to do it in the distance modality, we bring the active methodologies for the use in the distance modality even closer. The study also contributes to the expansion of the use of the TBL methodology in the online format.

There were some difficulties, such as the need for a safe and efficient internet network, as well as the dependence on the student's and teacher's digital knowledge.

The application of the fully online format also leads us to the need for further studies comparing learning efficiency, the opinion and preference of students and teachers between the traditional classroom and online format of the TBL strategy.

Finally, it is worth mentioning that the technologies are very dynamic, and when applying this TBL, we used the Moodle and Microsoft TEAMS platform, which brought together all the necessary functionalities, however, we can expect that other platforms will also evolve to allow greater access and more options at times such as this.

\section{Conflicts of Interest}

The authors declare no conflicts of interest regarding the publication of this paper. 


\section{References}

Amante, L., \& Quintas-Mendes, A. (2016). Distance Education, Open Education and Inclusion of Models Transmissive to Open Practices. Inclusão Social, 10, 49-65.

Amarilla Filho, P. (2011). Distance Education: A Methodological and Didactic Approach Based on Virtual Environments. Educação em Revista, 27, 41-72. https://doi.org/10.1590/S0102-46982011000200004

Barbosa, E. F., \& de Moura, D. G. (2013). Active Methodologies of Learning in Professional and Technological Education. Boletim Técnico do Senac, 39, 48-67. https://doi.org/10.26849/bts.v39i2.349

Bligh, J., \& Anderson, M. B. (2000). Medical Teachers and Evidence. Medical Education, 34, 162-163. https://doi.org/10.1046/j.1365-2923.2000.00648.x

Bollela, V. R., Senger, M. H., Tourinho, F. S. V., \& Amaral, E. (2014). Team-Based Learning: From Theory to Practice. Medicina (Ribeirão Preto), 47, 293-300. https://doi.org/10.11606/issn.2176-7262.v47i3p293-300

Borges, T. S., \& Alencar, G. (2014). Metodologias Ativas na promoção da formação crítica do Estudante: O uso das Metodologias Ativas como recurso didático na formação crítica do estudante do ensino superior. Cairu em Revista, 3, 119-143.

Brasil (1996). Presidência da República, Lei no 9.394 de 20 de dezembro de 1996. Diário Oficial da União, 134, 27833-27841.

Brasil (2014). Ministério da Educação., Resolução No. 3 de 20 de junho de 2014. Institui diretrizes curriculares nacionais do curso de graduação em Medicina e dá outras providências. Diário Oficial da União, 1, 8-11.

Brasil (2018). Ministério da Educação, Portaria n 1.428 de 28 de dezembro de 2018. Diário Oficial da União, 250, 59.

Brazil (2020) Ministry of Education Ordinance 345 of March 19, 2020 Federal Official Gazette (54-D) (p. 1).

Burgess, A. W., McGregor, D. M., \& Mellis, C. M. (2014). Applying Established Guidelines to Team-Based Learning Programs in Medical Schools: A Systematic Review. Academic Medicine, 89, 678-688. https://doi.org/10.1097/ACM.0000000000000162

Campos, F. E., Ferreira, J. R., Feuerwerker, L., de Sena, R. R., Campos, J. J. B., Cordeiro, H., \& Cordoni Jr., L. (2001). Ways the Attune Training of Health Professionals with Basic Health Care Needs. Revista Brasileira de Educação Médica, 25, 53-59.

Cross, P. K. (1987). Teaching for Learning. American Association for Higher Education Bulletin, 39, 3-7.

Cutolo, L. R. A., \& Delizoicov, D. (2003). Characterizing the Brazilian Medical School. Santa Catarina Archives of Medicine, 32, 24-34.

de Oliveira, B. L. C. A., Lima, S. F., L. Rodrigues, dos S., \& Pereira Júnior, G. A. (2018). Team-Based Learning as a Form of Collaborative Learning and Inverted Classroom with Centrality in Students in the Teaching-Learning Process. Revista Brasileira de Educação Médica, 42, 86-95. https://doi.org/10.1590/1981-52712015v42n4rb20180050

Freire, P. (1974). Pedagogia do oprimido. Editora Paz e Terra.

Gomes, R., Francisco, A. M., Tonhom, S. F. da R., da Costa, M. C. G., Hamamoto, C. G., Pinheiro, O. L., Moreira, H. M., \& Hafner, M. de L. M. B. (2009). Medical Training Anchored in Problem-Based Learning: A Qualitative Assessment. Interface, 13, 71-83. https://doi.org/10.1590/S1414-32832009000100007

Haidet, P., Levine, R. E., Parmelee, D. X., Crow, S., Kennedy, F., Kelly, P. A., Perkowski, L., Michaelsen, L., \& Richards, B. F. (2012). Perspective: Guidelines for Reporting 
Team-Based Learning Activities in the Medical and Health Sciences Education Literature. Academic Medicine, 87, 292-299.

https://doi.org/10.1097/ACM.0b013e318244759e

Krug, R. de R., Vieira, M. S. M., de Andrade e Maciel, M. V., Erdmann, T. R., de Faria Vieira, F. C., Koch, M. C., \& Grosseman, S. (2016). The "Bê-Á-Bá" of Team Based Learning. Revista Brasileira de Educação Médica, 40, 602-620. https://doi.org/10.1590/1981-52712015v40n4e00452015

Lampert, J. B., Aguilar-da-Silva, R. H., Perim, G. L., Stella, R. C. de R., Abdalla, I. G., \& Costa, N. M. S. C. (2009). Project for the Evaluation of Change Trends in the Undergraduate Course of Brazilian Medical Schools. Revista Brasileira de Educação Médica, 33, 5-18. https://doi.org/10.1590/S0100-55022009000500002

Legrand, L. (1976). A didática da reforma: Um método ativo para a escola de hoje. Editora Zahar.

Lundberg, L. G., Martenson, D., \& Brostrom, O. (2000). Learning among Medical Students-Teachers' Commitment a Decisive Factor. Lakartidningen, 97, 3750-3751.

Parmelee, D. X., \& Michaelsen, L. K. (2010). Twelve Tips for Doing Effective Team-Based Learning (TBL). Medical Teacher, 32, 118-122.

https://doi.org/10.3109/01421590903548562

Parmelee, D., Michaelsen, L. K., Cook, S., \& Hudes, P. D. (2012). Team-Based Learning: A Practical Guide: AMEE Guide No. 65. Medical Teacher, 34, e275-e287. https://doi.org/10.3109/0142159X.2012.651179

Quintas-Mendes, A., \& Wyszomirska, R. M. de A. F. (2018). Education and Teacher Training in the Context of Online Distance Education. Times and Spaces in Education Magazine, 11, 93-112.

Rao, S. P., \& DiCarlo, S. E. (2001). Active Learning of Respiratory Physiology Improves Performance on Respiratory Physiology Examinations. Advances in Physiology Education, 25, 55-61. https://doi.org/10.1152/advances.2001.25.2.55

Searle, N. S., Haidet, P., Kelly, P. A., Schneider, V. F., Seidel, C. L., \& Richards, B. F. (2003). Team Learning in Medical Education: Initial Experiences at Ten Institutions. Academic Medicine, 78, S55-S58. https://doi.org/10.1097/00001888-200310001-00018

Silberman, M. (1996). Active Learning: 101 Strategies Do Teach Any Subject. Boston, MA: Allyn and Bacon.

Silva, S. H. S. (1995). Speak Professor! Representations of Teaching and Learning. Proceedings of the 33rd Brazilian Congress on Medical Education, Porto Alegre, 22-27 October 1995, 350. 